Canadian

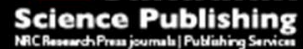

Canadian Journal of Microbiology Revue canadienne de de microbiologie

\title{
Probiotic Lactobacillus casei Expressing Porcine Antimicrobial Peptide PR39 Elevates Antibacterial Activity in the Gastrointestinal Tract
}

\begin{tabular}{|c|c|}
\hline Journal: & Canadian Journal of Microbiology \\
\hline Manuscript ID & cjm-2016-0130.R3 \\
\hline Manuscript Type: & Article \\
\hline Date Submitted by the Author: & 30-Jun-2016 \\
\hline Complete List of Authors: & $\begin{array}{l}\text { Zhang, Lei; Northeast Agricultural University, College of Veterinary } \\
\text { Medicine } \\
\text { Guo, Dian; Northeast Agricultural University, College of Veterinary Medicine } \\
\text { Liu, Yangxin; Northeast Agricultural University, College of Veterinary } \\
\text { Medicine } \\
\text { Shao, Yilan; Northeast Agricultural University, College of Veterinary } \\
\text { Medicine } \\
\text { Wang, Yufeng; Northeast Agricultural University, College of Veterinary } \\
\text { Medicine } \\
\text { Xu, Yigang; Northeast Agricultural University, College of Veterinary } \\
\text { Medicine } \\
\text { Jiang, Yanping; Northeast Agricultural University, College of Veterinary } \\
\text { Medicine } \\
\text { Cui, Wen; Northeast Agricultural University, College of Veterinary Medicine } \\
\text { Li, Yijing; Northeast Agricultural University, College of Veterinary Medicine, } \\
\text { Tang, Lijie; Northeast Agricultural University, College of Veterinary } \\
\text { Medicine }\end{array}$ \\
\hline Keyword: & $\begin{array}{l}\text { Antimicrobial peptide PR39, Lactobacillus casei, ecombinant expression, } \\
\text { antimicrobial activity }\end{array}$ \\
\hline
\end{tabular}

\section{SCHOLARONE \\ Manuscripts}


1 Probiotic Lactobacillus casei Expressing Porcine Antimicrobial Peptide PR39

2 Elevates Antibacterial Activity in the Gastrointestinal Tract

3

4 Running title: L. casei Expressing the Antimicrobial Peptide PR39

5

6 Lei Zhang, Dian Guo, Yangxin Liu, Yilan Shao, Yufeng Wang, Yigang Xu,

$7 \quad$ Yanping Jiang, Wen Cui, Yijing Li*, Lijie Tang*

8

9 College of Veterinary Medicine, Northeast Agricultural University, Harbin, China

10

11 *Correspondence:

12 Lijie Tang, Mucai Street 59, Xiang Fang District, Harbin, China

13 E-mail: tanglijie@163.com

14 Yijing Li, Mucai Street 59, Xiang Fang District, Harbin, China

15 E-mail: yijingli@neau.edu.cn 


\section{Abstract}

17 PR39, a 4.7-kDa proline-rich antimicrobial peptide, acts as a cationic host defense peptide. In 18 addition to killing bacteria, PR39 mediates inflammatory reactions, including cell 19 proliferation, migration, wound healing, and angiogenesis. Here, we examined the 20 antibacterial effects of this peptide. The synthetic gene fragment PR39 was inserted into the 21 secretory expression vector plasmid pPG:612 of Lactobacillus casei, yielding the 22 recombinant strain pPG:612-PR39/L. casei 393. In vitro antibacterial tests showed that 23 expression of the PR39 peptide in recombinant L. casei resulted in antibacterial activity 24 against Escherichia coli and Salmonella, but had only minor antibacterial effects in Staphylococcus aureus. In addition, BALB/c mice fed the recombinant pPG:612-PR39/L. casei 393 grew better and had increased peripheral blood lymphocyte percentages, white blood cell numbers, and spleen indices compared with those of the control group. Scanning electron microscopy showed that jejunum and duodenum villus height, crypt depth, and the ratio of $\mathrm{V} / \mathrm{C}$ in the intestinal villi also increased. Moreover, mice fed the recombinant strain showed significantly lower mortality rates than the control group when challenged with the enterotoxigenic E. coli $\mathrm{K} 88^{+}\left(\mathrm{ETEC} \mathrm{K} 88^{+}\right)$. Thus, this recombinant expression system had beneficial characteristics of both Lactobacillus casei and PR39, supporting its potential as an animal feed additive.

34 Keywords: Antimicrobial peptide PR39, Lactobacillus casei, recombinant expression, 35 antimicrobial activity 


\section{Introduction}

Antimicrobial peptides (AMPs) play fundamental roles in innate immunity owing to their direct antimicrobial activity and other functions (Bals 2000; Zasloff 2002). 2684 AMPs (266 bacteriocins from bacteria, 4 from archaea, 8 from protists, 13 from fungi, 329 from plants, and 2018 from animals) have been reported in the Antimicrobial Peptide Database (http://aps.unmc.edu/AP/main.php). These AMPs have antibacterial, antiviral (anti-human immunodeficiency virus [HIV]), antifungal, antiparasitic (antimalarial), anticancer, antiprotist, insecticidal, spermicidal, chemotactic, and antioxidant activities and can function as protease inhibitors. Among these endogenous AMPs, the $4.7 \mathrm{kDa}$ PR39, a member of the cathelicidin family, was first identified in pig intestinal tissue and later in neutrophilic granulocytes (Boman 1995; Sang and Blecha 2009; Zanetti 2004). Like other proline-arginine-rich peptides, PR39 has a broad antimicrobial spectrum against Escherichia coli ATCC 25922, E. coli K881, Salmonella Typhimurium, Salmonella Choleraesuis, Streptococcus suis, and Staphylococcus aureus (Shi et al. 1996). PR39 is thought to kill bacteria by interfering with DNA and/or protein synthesis (Boman et al. 1993), rather than changing membrane permeability (Litteri and Romeo 1993; Maloy and Kari 1995). However, the mechanism of action has not been fully elucidated (Deslouches et al. 2005; Dürr et al. 2006). Moreover, in addition to its known effects on the neutrophil NADPH oxidase in the context of host-derived inflammation, PR39 has also been shown to be effective for induction of angiogenesis and promotion of syndecan expression in mesenchymal cells (Gallo et al. 1994; Li et al. 2000; Korthuis et al. 1999). PR39 has also been reported to have immunomodulatory functions (Zhu et al. 2012), antitumor activity, and therapeutic effects in the treatment of ischemic heart disease (Gler et al. 2012). Considering its high proline content, PR39 shows high stability in solution and is resistant to serine proteases, elastase, and amino peptidases, resulting in a long half-life (Sang and Blecha 2009); these properties make PR39 a promising therapeutic agent. 
The synthesis and purification of AMPs are costly and time-consuming; therefore, an economical expression system that could produce large quantities of AMPs is needed. E. coli is one of the most widely used hosts for the production of heterologous proteins (Terpe 2006). However, the expressed proteins are usually found within inclusion bodies and are therefore often inactive, insoluble, and incorrectly folded (Demain and Vaishnav 2009). Alternatively, lactic acid-producing bacteria (LAB) are generally regarded as safe organisms and are therefore widely used in the production and preservation of fermented products by the food industry. Lactobacillus casei has been considered a good candidate to serve as a cost-effective live vaccine delivery vehicle for mucosal immunization. L. casei participate in the body's metabolic pathways and play important roles in the body's immune system. With excellent colonization ability, L. casei exist in the mucosa and continue to multiply, allowing sustained production and release of the target protein. As vaccine vectors, L. casei could be taken orally and as they exhibit tolerance to acid and bile salt (Yuki and Kiyono 2009).

In this study, we aimed to express PR39 in Lactobacillus casei 393 using a shuttle expression vector to provide both the probiotic effects (Douillard et al. 2013) of L. casei 393 and the biological function of PR39.

\section{Materials and methods}

\section{Plasmids and strains}

To obtain Staphylococcus aureus CVCC26003, E. coli CVCC10141, Salmonella enterica subsp. enterica Choleraesuis CVCC79102, and enterotoxigenic E. coli $\mathrm{K}^{2} 8^{+}$(ETEC K88 ${ }^{+}$) CVCC230 at mid-logarithmic-phase, these organisms were cultured for $8 \mathrm{~h}$ at $37^{\circ} \mathrm{C}$ in Luria broth (LB). L. casei 393 was grown in MRS (De Man et al. 1960) (Sigma, St. Louis, MO, USA) supplemented with $0.1 \%(\mathrm{v} / \mathrm{v})$ Tween -80 at $37^{\circ} \mathrm{C}$ without shaking.

A DNA fragment, (SacI) GAGCTCGAACAAAAGTTGATTTCAGAAGAAGATTTA 
(Myc-tag)AGGAGACGTCCCCGACCCCCATATTTGCCAAGGCCAAGGCCACCTCCGT TTTTCCCACCAAGGCTCCCACCAAGGATCCCACCAGGGTTCCCACCAAGGTTCCC ACCACGGTTCCCCGGATAATGACTCGAG(XhoI), encoding PR39 and an extra myc-tag, was inserted into the plasmid pPG:612 (obtained from Prof. Seegers, NIZO Institute, Netherlands; this plasmid contains the secretion signal peptide for secretory expression) between $S a c$ I and XhoI to construct the expression plasmid pPG:612-PR39. The fragment encoding PR39 was obtained by gene synthesis (DNA2.0 Co. Ltd) based on the bias of $L$. casei 393. The ligated product was then transformed into E. coli TG1 cells to screen the positive plasmid before transforming this plasmid into L. casei 393.

Competent L. casei 393 were prepared as previously described (Landete et al. 2014), and $2 \mu \mathrm{L}$ recombinant plasmid was then mixed with $200 \mu \mathrm{L}$ ice-cold competent cells. The mixture was incubated in an ice bath for $5 \mathrm{~min}$ and then transferred to a precooled Gene Pulser disposable cuvette (interelectrode distance: $0.2 \mathrm{~cm}$ ) before delivery of a single electrical pulse $(2,000 \mathrm{~V} / \mathrm{cm}, 2.5 \mu \mathrm{F})$. Immediately, $800 \mu \mathrm{L}$ of recovery medium (MRS broth with $15 \%$ sucrose) was added to the suspension, and the bacteria were then incubated for $2 \mathrm{~h}$ at $37^{\circ} \mathrm{C}$ for recovery. Recombinant strains were selected on MRS agar medium containing $5 \mu \mathrm{g} / \mathrm{mL}$ chloramphenicol $(\mathrm{Cm})$. Identification was performed via extraction of recombinant plasmid DNA, followed by restriction analysis and sequencing. The strains and plasmids used in this study are shown in Table 1.

\section{Western blot analysis}

To analyze the expression of PR39 by pPG:612-PR39 in L. casei 393, recombinant strains were cultured for $20 \mathrm{~h}$ in MRS broth containing $\mathrm{Cm}(10 \mu \mathrm{g} / \mathrm{mL})$ and xylose $(10 \mathrm{~g} / \mathrm{L})$ as a supplement at $37^{\circ} \mathrm{C}$. Both bacterial and trichloroacetic acid (TCA)-treated supernatants (a 10-fold concentration) were analyzed by sodium dodecyl sulfate-polyacrylamide gel electrophoresis on $12 \%$ gels. Proteins were then transferred to nitrocellulose membranes, 
112 soaked in blocking solution (5\% skim milk in phosphate-buffered saline [PBS]) for $2 \mathrm{~h}$, and

113 immersed in primary antibodies (monoclonal mouse anti-Myc antibodies; 1:500; Santa Cruz

114 Biotechnology, Santa Cruz, CA, USA) at $4^{\circ} \mathrm{C}$ overnight. Membranes were then washed and

115 incubated with horseradish peroxide (HRP)-conjugated secondary goat anti-mouse IgG

116 (1:3000 dilution; Sigma) for $2 \mathrm{~h}$ at $37^{\circ} \mathrm{C}$. Finally, we visualized the film was visualised with

117 freshly prepared 4-chloro-1-naphthol- $\mathrm{H}_{2} \mathrm{O}_{2}$ solution.

118 Growth performance of the recombinant strain

119 To investigate the influence of exogenous genes on the growth performance of the 120 recombinant strain, mid-logarithmic-phase pPG:612-PR39/L. casei 393 and pPG:612/L. casei 121393 were inoculated in MRS broth with $\mathrm{Cm}$ (1/20 inoculum). When the $\mathrm{OD}_{600}$ values of both 122 cultures reached 2 , we added $1 \%$ xylose to each culture and induced the cultures for $24 \mathrm{~h}$. The $123 \mathrm{OD}_{600}$ was measured every $2 \mathrm{~h}$ to create a growth curve. A replicate experiment was 124 performed without induction; in this experiment, mid-logarithmic-phase pPG:612-PR39/L. 125 casei 393 and pPG:612/L. casei 393 were inoculated in MRS broth with Cm (1/50 inoculum) 126 and cultured for $24 \mathrm{~h}$.

127 Antibacterial activity in vitro

128 Staphylococcus aureus CVCC26003, E. coli CVCC10141, and Salmonella enterica subsp. 129 enterica Choleraesuis CVCC79102 were grown for $8 \mathrm{~h}$ at $37^{\circ} \mathrm{C}$ in $\mathrm{LB}$ and collected at 130 mid-logarithmic-phase. Next, $1 \mathrm{~mL}$ of the concentrated supernatant of each recombinant 131 strain was mixed with $9 \mathrm{~mL} \mathrm{LB}$, and the above bacteria were inoculated into the mixture. 132 Cultures were incubated for $8 \mathrm{~h}$ on a rotary shaker at $37^{\circ} \mathrm{C}$, and the $\mathrm{OD}_{600}$ values were 133 measured using a spectrophotometer before plotted the growth curves.

134 Animal experiments and growth performance

135 All procedures used in this study were approved by the Institutional Animal Care and Use 136 Committee of Northeast Agricultural University, China. Three random groups $(n=9$ per 
137 group) of female BALB/c mice (6 weeks old) were housed in individual ventilation cages 138 (IVCs; temperature, $32.70 \pm 2.99^{\circ} \mathrm{C}$; relative humidity, $77.54 \% \pm 2.34 \%$; THI, 139 temperature-humidity index, 87.27) and fed ad libitum. The grouped animals were orally 140 dosed with $200 \mu \mathrm{L}\left(10^{9} \mathrm{CFU} / \mathrm{mL}\right)$ inoculum of pPG:612-PR39/L. casei 393, pPG:612/L. 141 casei 393, and MRS broth. The recombinant bacteria was induced as previously described. 142 Mice were treated via the oral route for 28 days using pPG:612/L. casei 393 and MRS broth 143 as control groups. The mice were maintained under strict conditions according to 144 international recommendations for animal welfare. The initial weights of mice in each group 145 were measured, and food intake and weight gain were determined each day. These growth 146 performance parameters, including average weekly feed intake (AWFI), average daily gain 147 (ADG), and feed/gain $(\mathrm{F} / \mathrm{G})$ ratio, were calculated throughout the 28-day experimental 148 period.

149 Sample collection

150 On day 28 , blood samples and the spleen and small intestine were collected from three randomly chosen mice from each group, blood samples were analyzed the lymphocyte 152 percentages and leukocyte counts. The spleen index was calculated using the following 153 formula: spleen index $=($ spleen weight $/$ body weight $) \times 10$. In addition, the morphology of 154 small intestine villi was observed by scanning electron microscopy (SEM). Fecal samples 155 were collected on days 0 and 28 (6 g per group), and fecal DNA was extracted using a gel midi purification kit (TIANGEN Biotech (Beijing) Co., Ltd., Beijing, China) according to the manufacturer's protocol. The V3 region of the 16S-rRNA was amplified for analysis of bacterial diversity using synthetic universal bacterial primers (Sangon Biotech Co., Ltd.), as follows:

forward primer

GC-338F (5'-CGCCCGGGGCGCGCCCCGGGGCGGGGCGGGGGCGCGGGGGGCCTACGGGAG

161 GCAGCAG-3'), and reverse primer 518R (5'-ATTACCGCGGCTGCTGG-3') ( Yu, Z. and M. Morrison. 2004). The polymerase chain reaction (PCR) fragments were separated by denaturing gradient gel electrophoresis (DGGE) with the following protocol: $8 \%$ 
164 polyacrylamide (v/v; ratio of acrylamide:bisacrylamide [37.5:1]) in $1 \times$ TAE buffer, gradient 165 ranging from $20 \%$ to $35 \%$ denaturant $(100 \%$ denaturant acrylamide corresponding to $7 \mathrm{M}$ 166 urea and $40 \%\left[\mathrm{v} / \mathrm{v}\right.$ ] formamide). Electrophoresis was carried out at $65^{\circ} \mathrm{C}$ for $14 \mathrm{~h}$ in $1 \times \mathrm{TAE}$ 167 buffer, with a constant voltage of $100 \mathrm{~V}$. After electrophoresis, gels were stained with silver 168 nitrate for $30 \mathrm{~min}$, photographed using a UVR-800 instrument (Bio-Rad, Hercules, CA, USA), 169 and analyzed by Quantity One 4.6.2. Using these data, the Shannon-Wiener diversity index, 170 richness, and evenness were calculated.

171 Challenge with the ETEC K88 $8^{+}$strain

172 To confirm the minimal lethal dose (MLD) of ETEC $\mathrm{K}^{+} 8^{+}$in mice three random groups ( $\mathrm{n}=$ 1736 per group) of female BALB/c mice (6 weeks old) were housed under the same conditions 174 and challenged with $200 \mu \mathrm{L}$ different amounts of ETEC $\mathrm{K}^{+} 8^{+}$before the protection 175 experiments.

176 Next, we investigated the protective effects of the recombinant strain against ETEC K88 ${ }^{+}$. On 177 day 29, the remaining 18 mice (6 per group) from above animal experiments after sample 178 collection were challenged with an MLD oral dose $\left(2 \times 10^{8} \mathrm{CFU} / \mathrm{mL}\right)$ of ETEC $\mathrm{K} 88^{+}$, and death occurring within $24 \mathrm{~h}$ was observed.

Statistical analysis

SPSS Statistics v17.0 software (International Business Machines Corporation, NY, USA) was 182 used for single-factor analysis of variance. Bacterial numbers were log transformed using the population estimate. Differences between groups with probability values of less than 0.05 were considered statistically significant using Duncan's multiple comparisons test.

\section{Results}

\section{Protein localization}

188 Western blot analysis showed that the target protein was present in both the sediment and 
189 supernatants of the recombinant strain. The protein identified in sediment of 190 pPG:612-PR39/L. casei 393 was $36 \mathrm{kDa}$; this was approximately 5 times higher than the predicted size derived from the amino acid sequence of PR39 and myc tag (total $6 \mathrm{kDa}$ approximately). In contrast, that in the supernatant was 2 times larger at $18 \mathrm{kDa}$ (Fig. 1). Influence of PR39 on the growth of recombinant L. casei

194 Growth curves showed that the two strains had similar growth trends, indicating that the 195 exogenous gene encoding PR39 did not alter the growth of the recombinant strain. Because 196 PR39 has antimicrobial activity in some gram-positive bacteria (Freer et al. 1999), the growth curves of induced recombinant strains were also analysed. Similarly, the data suggested that the exogenous protein did not influence the growth of the recombinant strains (Fig. 2a, 2b). Antimicrobial test in vitro

As shown in Figure 3a and 3b, the recombinant strain had a certain degree of antimicrobial activity against E. coli CVCC10141 and Salmonella enterica subsp. enterica Choleraesuis CVCC79102. However, the recombinant strain did not have antimicrobial activity against $S$. aureus CVCC26003 (Fig. 3c).

Growth performance of mice

Compared with mice in the control groups, mice in the experimental group fed the recombinant strain exhibited higher weight gain. After 28 days, the F/G ratio of mice in the experimental group (pPG:612-PR39/L. casei 393) was significantly lower $(P<0.01)$ than that of mice in the control groups (MRS broth and pPG:612/L. casei 393 ; Table 2). Thus, these results demonstrated that expression of PR39 by the recombinant strain promoted the growth performance of mice.

Immunomodulatory function

212 Analysis of lymphocyte percentages and leukocyte numbers in blood samples showed that 213 mice in the experimental group had significantly higher lymphocyte percentages and 
214 leukocyte counts than mice in the control groups $(P<0.05$; Table 2). Additionally, mice in

215 the control groups exhibited significantly higher spleen indices than mice in the experimental $216 \operatorname{group}(P<0.05$; Table 2$)$.

217 Effects on intestinal villus morphology

218 Observation Measurement of villus height and intestinal crypt depth in the duodenum and 219 jejunum by SEM (Fig. 4) showed that villus height was significantly higher in the 220 experimental group than in the control group $(P<0.01)$. However, there was no obvious 221 difference in intestinal crypt depth. Notably, the V/C value in the experimental group was 222 significantly higher than that in the control group $(P<0.01)$. In addition, observation of the 223 small intestine villus morphology showed that the recombinant antibacterial peptide 224 improved the structure of the intestinal mucosa in mice (Table 3).

225 Diversity of the intestinal microbiota

226 The V3 region of 16S-rRNA in fecal samples was amplified with synthetic universal bacterial 227 primers to obtain an amplification fragment of approximately $240 \mathrm{bp}$ (Fig. 5). The PCR 228 fragments were separated by DGGE to investigate the diversity of the intestinal microbiota. 229 Analysis of the DGGE map (Fig. 6 ) showed that there were no significant changes in 230 richness (Richness, S) during the experiment. However, the diversity（Shannon-Wiener, $231 H$ ) and evenness (Evenness, E) indices of the experimental group were decreased(Table $2324)$.

\section{Protection against ETEC K88}

234 The minimal lethal dose (MLD) of ETEC K $88^{+}$in mice was $2 \times 10^{8} \mathrm{CFU} / \mathrm{mL}$ (Table 5). After 235 oral challenge using the MLD, the mortality rates in the MRS, pPG:612/L. casei 393, and 236 experimental groups were $100 \%, 83 \%$, and 33\%, respectively (Table 6). These results 237 suggested that the recombinant strains were effective and that peptide PR39 could protect 238 mice from ETEC $\mathrm{K} 88^{+}$to some extent. 


\section{Discussion}

In this study, we expressed PR39 in L. casei 393 and examined the effects of PR39 on

bacterial growth. Our results demonstrated that PR39 could protect mice from bacterial infection when expressed in L. casei 393, providing support for the evaluation of this system as a functional food additive.

codon bias of $L$. casei and contained a c-myc tag to facilitate protein detection. Notably, we found that the expressed protein was $36 \mathrm{kDa}$ in the pellet of bacteria and $18 \mathrm{kDa}$ in the supernatant of the culture (Figure 1), i.e., approximately 5 and 2 times larger than the predicted molecular weights. Previous data have shown that when PR39 is inserted into the pGEX-4T-1 plasmid, a vector used to produce a fusion protein with GST, and expressed in $E$. coli, the targeted protein was $31 \mathrm{kDa}$, as predicted (Fan et al. 2010). This discrepancy may be explained by the different sizes of the protein tags; for example, the fusion protein is predicted to be a $6-\mathrm{kDa}$ protein, which is much smaller than the predicted $31-\mathrm{kDa}$ protein and therefore may be more prone to formation of polymers. Accordingly, the 36-kDa secreted protein in the pellet from the recombinant $L$. casei may be a hexamer of the fusion protein (Zhu et al. 2012), and that in the supernatant $(18 \mathrm{kDa})$ may be a trimer, produced during ultrasonication.

AMPs are well known for their diverse functions, the most important of which is their antimicrobial activity. PR39 exhibits a broad antimicrobial spectrum, affecting E. coli, Salmonella Typhimurium, Acinetobacter calcoaceticus, Bacillus anthracis, and Streptococcus pyogenes (Agerberth et al. 1991). Additionally, in this study, we found that PR39 inhibited the growth of Salmonella enterica subsp. enterica Choleraesuis and E. coli, whereas $S$. aureus was insensitive to PR39 (Figure 3). Notably, PR39 did not affect the growth of 
264 recombinant L. casei (Figure 3). Studies have indicated that Pro-Arg-rich AMPs are more 265 effective against Gram negative bacteria than against Gram positive bacteria, which are 266 consistent with the expected results of this experiment (Scocchi et al. 2011). Several studies 267 have suggested that PR39 may act through a nonlytic mechanism (Casteels et al. 1989; 268 Boman et al. 1993) by interfering with DNA and/or protein synthesis (Shi et al. 1996). Thus, 269 these data confirmed the antibacterial effects of PR39 in vivo.

270 In addition to killing bacteria directly, AMPs have been shown to have several 271 immunoregulatory functions and may be involved in the clearance of infection, including 272 alteration of host gene expression, function as chemokines, induction of chemokine 273 production, inhibition of lipopolysaccharide induced pro-inflammatory cytokine production 274 (Davidson et al. 2004), promotion of wound healing, modulation of dendritic cell responses, 275 and promotion of the adaptive immune response ( $\mathrm{Li}$ et al. 2000; Korthuis et al. 1999). 276 Previous studies have indicated that these AMPs also play important roles in protecting the 277 organism from pathogen infection. Moreover, AMPs act as signal transduction molecules between innate immunity and specific immunity to promote the host-specific immune response and expand the biological activity of the immune system. PR39 can reduce inflammation, promote wound healing, and activate neutrophils by inducing syndecans (Huang et al. 1997). Full-length PR39 is capable of inducing the expression of interleukin (IL)-8, whereas N-terminal PR39-derived peptides are sufficient for antimicrobial activity and can stimulate tumor necrosis factor (TNF)- $\alpha$ production by macrophages (Veldhuizen et al. 2014). Moreover, another study showed that PR39 can act as a $\mathrm{Ca}^{2+}$-dependent chemoattractant of neutrophils, demonstrating the important role of PR39 in inflammation (Huang et al. 1997). Consistent with these findings, we found that mice in the experimental group in our study exhibited better growth performance (Table 2) and increased immune capacity following oral dosing with recombinant L. casei. Notably, the growth performance 
and immune status in the $L$. casei control group were better than those in the MRS group, suggesting that improvement of performance in mice in the experimental group could be attributed to both the expressed PR39 and the probiotic L. casei.

Several reports have described the efficiency of recombinant LAB for both oral and intranasal immunization. Some studies have shown higher immune responses after oral immunization with recombinant LAB (Cheun et al. 2004; Ramasamy et al. 2006). Consistent with this, our study showed that the recombinant strain had antimicrobial activity and immunomodulatory functions and improved intestinal health, as shown by our results of DGGE-PCR (Table 4 and Figure 6) and SEM images (Table 3 and Figure 4). The beneficial effects of recombinant Lactobacillus may be explained by several mechanisms. First, changes in metabolites of bacterial fermentation and enhancement of intestinal motility may be explained by changes in the compositions of the intestinal microbiota, which could be attributed to reduction of the $\mathrm{pH}$ value or shortening of the transit time. Bacterial production of organic acids (lactic acid, butyric acid, and propionic acid) results in a decrease in $\mathrm{pH}$ and affects the reabsorption of electrolytes and water, thereby changing the osmotic pressure and promoting intestinal motility (Salminen and Salminen 1996). After oral challenge using the E.coli, the mortality rates was reduced clearly in recombinant strains than MRS group (Table 6), the result suggested that L.casei, as nonpathogenic microorganisms in the gastrointestinal microbiota, could be a good choice for enhancing intestinal health. In fact, several AMPs have been successfully expressed by probiotics (Mandal et al. 2014). In our case, L. casei 393 was chosen to express PR39, and there was no need for protein purification. This system has advantages of both AMPs and probiotics. More importantly, as a carrier, LAB can be taken orally; this is considered a major advantage and convenience. In recent years, recombinant Lactobacillus expressing antibacterial peptides have been shown to have a unique advantage, and the development of food-grade Lactobacillus vectors has great potential as an important 
314 food additive.

315 In conclusion, in our experimental setup, the codon-optimized gene of PR39 was 316 inserted into a shuttle expression vector and expressed in L. casei 393 successfully. Our

317 findings confirmed that the expressed fusion protein was capable of inhibiting the growth of 318 two pathogenic bacteria in vitro and that the recombinant strain was beneficial to animals 319 owing to both the expression of PR39 and the probiotic properties of L. casei 393.

320

321

\section{Conflict of Interest}

The authors declare that they have no conflicts of interest.

\section{Acknowledgements}

This study was supported by grant nos. 31072057 and 30871809 from the National Natural Science Fund of China. We would like to thank Prof. Jos Seegers for providing the plasmid pPG:612 and the Institutional Animal Care and Use Committee of Northeast Agricultural University. We also would like to thank Editage[http://online.editage.cn/] for English language editing.

\section{References}

Agerberth, B., Lee, J.Y., Bergman, T., Carlquist, M., Boman, H.G., Mutt, V., and Jornvall, H. 1991. Amino acid sequence of PR-39. Isolation from pig intestine of a new member of the family of proline-arginine-rich antibacterial peptides. Eur. J. Biochem. 202(3), 849-854.

Bals, R. 2000. Epithelial antimicrobial peptides in host defense against infection. Respir. Res. 1(3), 141.

Boman, H.G. 1995. Peptide antibiotics and their role in innate immunity. Ann. Rev. Immunol. 13, 61-92.

Casteels, P., Ampe, C., Jacobs, F., Vaeck, M., and Tempst, P. 1989. Apidaecins: antibacterial 
340 peptides from honeybees. EMBO J. 8(8), 2387.

341 Cheun, H., Kawamoto, K., Hiramatsu, M., Tamaoki, H., Shirahata, T., Igimi, S., and Makino, 342 S.I. 2004. Protective immunity of SpaA-antigen producing Lactococcus lactis against 343 Erysipelothrix rhusiopathiae infection. J. Appl. Microbiol. 96(6), 1347-1353.

344 Davidson, D.J., Currie, A.J., Reid, G.S., Bowdish, D.M., MacDonald, K.L., Ma, R.C., 345 Hancock, R.E., and Speert, D.P. 2004. The cationic antimicrobial peptide LL-37 modulates 346 dendritic cell differentiation and dendritic cell-induced $\mathrm{T}$ cell polarization. J. Immunol. $347 \quad$ 172(2), 1146-1156.

348 De Man, J., Rogosa, D., and Sharpe, M.E. 1960. A medium for the cultivation of lactobacilli. 349 J. Appl. Bacteriol. 23, 130-135.

350 Demain, A.L., and Vaishnav, P. 2009. Production of recombinant proteins by microbes and 351 higher organisms. Biotechnol. Adv. 27(3), 297-306.

352 Douillard FP, Ribbera A, Jarvinen HM, Kant R, Pietila TE, Randazzo C, Pietilä TE., 353 Randazzo C., Paulin L., Laine P.K., Caggia C., Ossowski I.V., Reunanen J., Satokari R., 354 Salminen S., Palva A., de Vos W.M. 2013. Comparative genomic and functional analysis of 355 Lactobacillus casei and Lactobacillus rhamnosus strains marketed as probiotics. Appl 356 Environ Microbiol. 79(6):1923-33. Fan, F., Wu, Y., and Liu, J. 2010. Expression and purification of two different antimicrobial 358 peptides, PR-39 and Protegrin-1 in Escherichia coli. Prot. Expr. Purif. 73(2), 147-151.

359 Freer, E., Pizarro-Cerdá, J., Weintraub, A., Bengoechea, J.-A., Moriyón, I., Hultenby, K., 360 Gorvel, J.-P., and Moreno, E. 1999. The outer membrane of Brucella ovis shows increased 361 permeability to hydrophobic probes and is more susceptible to cationic peptides than are the 362 outer membranes of mutant rough Brucella abortus strains. Infect. Immun. 67(11), $363 \quad 6181-6186$.

364 Gler, M.T., Skripconoka, V., Sanchez-Garavito, E., Xiao, H., Cabrera-Rivero, J.L., 
365 Vargas-Vasquez, D.E., Gao, M., Awad, M., Park, S.-K., and Shim, T.S. 2012. Delamanid for multidrug-resistant pulmonary tuberculosis. N. Engl. J. Med. 366(23), 2151-2160.

367 Huang, H.-J., Ross, C.R., and Blecha, F. 1997. Chemoattractant properties of PR-39, a 368 neutrophil antibacterial peptide. J. Leukoc. Biol. 61(5), 624-629.

369 Korthuis, R.J., Gute, D.C., Blecha, F., and Ross, C.R. 1999. PR-39, a proline/arginine-rich 370 antimicrobial peptide, prevents postischemic microvascular dysfunction. Am. J. Physiol. 371 Heart Circ. Physiol. 277(3 Pt 2), H1007-H1013.

372 Landete, J.M., Arqués, J.L., Peirotén, Á., Langa, S., and Medina, M. 2014. An improved 373 immunisations. Vaccine 24(18), 3900-3908.

Salminen, S., and Salminen, E. 1996. Lactulose, lactic acid bacteria, intestinal microecology and mucosal protection. Scand. J. Gastroenterol. Suppl. 222, 45-48. 
390 functions. Dev. Comp. Immunol. 33(3), 334-343.

391 Scocchi, M., Tossi, A., and Gennaro, R. 2011. Proline-rich antimicrobial peptides: converging 392 to a non-lytic mechanism of action. Cell. Mol. Life Sci. 68(13), 2317-2330.

393 Shi, J., Ross, C.R., Chengappa, M., and Blecha, F. 1994. Identification of a 394 proline-arginine-rich antibacterial peptide from neutrophils that is analogous to PR-39, an 395 antibacterial peptide from the small intestine. J. Leukoc. Biol. 56(6), 807-811.

396 Shi, J., Ross, C.R., Chengappa, M., Sylte, M.J., McVey, D.S., and Blecha, F. 1996a. 397 Antibacterial activity of a synthetic peptide (PR-26) derived from PR-39, a 398 proline-arginine-rich neutrophil antimicrobial peptide. Antimicrob. Agents Chemother. 40(1), $399 \quad 115-121$.

400 Shi, J., Ross, C.R., Leto, T.L., and Blecha, F. 1996b. PR-39, a proline-rich antibacterial 401 peptide that inhibits phagocyte NADPH oxidase activity by binding to Src homology 3 402 domains of p47 phox. Proc. Natl. Acad. Sci. U. S. A. 93(12), 6014-6018.

403 Terpe, K. 2006. Overview of bacterial expression systems for heterologous protein 404 production: from molecular and biochemical fundamentals to commercial systems. Appl. 405 Microbiol. Biotechnol. 72(2), 211-222.

406 Yuki, Y., and Kiyono, H. 2009. Mucosal vaccines: novel advances in technology and delivery. 407 Expert. Rev. Vaccines 8(8), 1083-1097.

408 Yu, Z. and M. Morrison. 2004. Comparisons of different hypervariable regions of rrs genes 409 for use in fingerprinting of microbial communities by PCR-denaturing gradient gel 410 electrophoresis. Appl Environ Microbiol 70(8): 4800-4806.

411 Zanetti, M. 2004. Cathelicidins, multifunctional peptides of the innate immunity. J. Leukoc. 412 Biol. 75(1), 39-48.

413 Zasloff, M. 2002. Antimicrobial peptides of multicellular organisms. Nature 415(6870), $414 \quad 389-395$. 
415 Zhu, B., Liu, H., Tian, W.-X., Fan, X.-Y., Li, B., Zhou, X.-P., Jin, G.-L., and Xie, G.-L. 2012.

416 Genome sequence of Stenotrophomonas maltophilia RR-10, isolated as an endophyte from

417 rice root. J. Bacteriol. 194(5), 1280-1281. 
418 Table 1. Strains and plasmids used in this study.

410

\begin{tabular}{|c|c|c|}
\hline Strain or plasmid & Relevant characteristics or description & Reference or source \\
\hline \multicolumn{3}{|l|}{ Strains } \\
\hline Lactobacillus casei ATCC 393 & Plasmid-free wild-type strain & de Vos 1999 \\
\hline Escherichia coli CVCC10141 & Standard strain & China Veterinary Culture Collection Center \\
\hline $\begin{array}{l}\text { Salmonella enterica subsp. enterica } \\
\text { choleraesuis CVCC79102 }\end{array}$ & Standard strain & China Veterinary Culture Collection Center \\
\hline Enterotoxigenic $E$. coli $\mathrm{K}^{2} 8^{+} \mathrm{CVCC} 230$ & Standard strain & China Veterinary Culture Collection Center \\
\hline \multicolumn{3}{|l|}{ Plasmids } \\
\hline pPG:612 & $\mathrm{Cmr}$, repA + , and repC + & de Vos 1999 \\
\hline pPG:612-PR39 & pPG:612 with a copy of PR39 cloned SacI and XhoI sites & This study \\
\hline
\end{tabular}


420 Table 2. Effects of antimicrobial peptides on growth performance, spleen index,

421 lymphocyte percentages in peripheral blood, and white blood cell numbers in mice.

\begin{tabular}{|c|c|c|c|c|c|c|}
\hline \multirow[b]{2}{*}{ Treat } & \multicolumn{3}{|c|}{ Growth Index } & \multirow[b]{2}{*}{$\begin{array}{l}\text { Spleen } \\
\text { index }\end{array}$} & \multirow[b]{2}{*}{$\begin{array}{l}\text { White blood cell } \\
\text { numbers }\left(10^{9} / \mathrm{L}\right)\end{array}$} & \multirow[b]{2}{*}{$\begin{array}{c}\text { Lymphocyte percentage in } \\
\text { peripheral blood }(\%)\end{array}$} \\
\hline & $\begin{array}{l}\text { Total feed } \\
\text { intake (g) }\end{array}$ & $\begin{array}{c}\text { Total weight } \\
\text { gain (g) }\end{array}$ & Feed/gain & & & \\
\hline MRS & $115.730 \pm 2.6$ & $2.870 \pm 0.14$ & $40.200 \pm 0.78$ & $3.666 \pm 0.20$ & $3.20 \pm 0.10$ & $83.00 \pm 1.30$ \\
\hline pPG:612/L. casei 393 & $119.000 \pm 4.0$ & $2.795 \pm 0.20$ & $42.576 \pm 0.91$ & $3.747 \pm 0.14$ & $3.45 \pm 0.05$ & $84.40 \pm 1.00$ \\
\hline pPG:612-PR39/L. casei & $114.474 \pm 2.8$ & $3.695 \pm 0.17$ & $30.935 \pm 0.87^{\mathrm{bd}}$ & $4.245 \pm$ & $4.00 \pm 0.10^{\mathrm{ac}}$ & $91.25 \pm 1.30^{\mathrm{ac}}$ \\
\hline 393 & & & & $0.27^{\mathrm{ac}}$ & & \\
\hline
\end{tabular}

422 Values represent the mean \pm SD. ${ }^{\mathrm{a}} P<0.05$ and ${ }^{\mathrm{b}} P<0.01$ for comparisons of

423 pPG:612-PR39/L. casei 393 with MRS; ${ }^{\mathrm{c}} P<0.05$ and ${ }^{\mathrm{d}} P<0.01$ for comparisons of

424 pPG:612-PR39/L. casei 393 with pPG:612/L. casei 393. 
425 Table 3. Effects on the villous height, crypt depth, and $\mathrm{V} / \mathrm{C}$ of the jejunum and 426 duodenum of mice.

\begin{tabular}{|c|c|c|c|c|c|c|}
\hline \multirow[b]{2}{*}{ Treatment } & \multicolumn{3}{|c|}{ Jejunum } & \multicolumn{3}{|c|}{ Duodenum } \\
\hline & Villous height & Crypt depth & $\mathrm{V} / \mathrm{C}$ & Villous height $x$ & Crypt depth & $\mathrm{V} / \mathrm{C}$ \\
\hline MRS & $275.50 \pm 15.00$ & $88.30 \pm 5.20$ & $2.88 \pm 0.18$ & $308.33 \pm 3.80$ & $78.40 \pm 3.20$ & $3.54 \pm 0.24$ \\
\hline pPG:612/L. casei 393 & $260.00 \pm 14.00$ & $76.97 \pm 3.30$ & $3.38 \pm 0.28$ & $322.00 \pm 13.70$ & $76.60 \pm 4.80$ & $4.20 \pm 0.11$ \\
\hline pPG:612-PR39/L. casei & $304.47 \pm 11.00^{\mathrm{bd}}$ & $78.54 \pm 4.20$ & $4.70 \pm 0.32^{\mathrm{bd}}$ & $367.73 \pm 6.10^{\mathrm{bd}}$ & $76.70 \pm 8.20$ & $4.92 \pm 0.48^{\mathrm{bc}}$ \\
\hline 393 & & & & & & \\
\hline
\end{tabular}

427 Values represent the mean \pm SD. ${ }^{\mathrm{a}} P<0.05$ and ${ }^{\mathrm{b}} P<0.01$ for comparisons of

428 Ppg:612-PR39/L. casei 393 with MRS; ${ }^{\mathrm{c}} P<0.05$ and ${ }^{\mathrm{d}} P<0.01$ for comparisons of 429 pPG:612-PR39/L. casei 393 with pPG:612/L. casei 393. 
430 Table 4. Diversity indices calculated from the DGGE banding profiles.

\begin{tabular}{ccccccc}
\hline & $\mathbf{A}_{\mathbf{0}}$ & $\mathbf{A}_{\mathbf{2 8}}$ & $\mathbf{B}_{\mathbf{0}}$ & $\mathbf{B}_{28}$ & $\mathbf{C}_{\mathbf{0}}$ & $\mathbf{C}_{28}$ \\
\hline $\mathbf{H}$ & 3.98 & 3.91 & 3.68 & 3.76 & 3.61 & 3.48 \\
$\mathbf{S}$ & 45 & 45 & 40 & 40 & 41 & 40 \\
$\mathbf{E}$ & 1.04 & 1.04 & 1.08 & 1.07 & 1.06 & 0.85 \\
\hline
\end{tabular}

431 A. MRS group; B. pPG: 612/L. casei 393 group; C. pPG:612-PR39/L. casei 393

432 group. $\mathrm{H}, \mathrm{S}$ and $\mathrm{E}$ represents diversity, richness and evenness, respectively. Analyses

433 of DGGE maps were performed with Quantity One 4.6.2 software; the

434 pPG:612-PR39/L. casei 393 group was compared with the control group, richness was

435 unchanged, and Shannon-Wiener and evenness were reduced. 
436 Table 5. Mortality of mice after challenge with different amounts of $\mathrm{K} 88^{+}$ETEC.

\begin{tabular}{lcccc}
\hline Group & Number of mice & Challenge dose (CFU/mL) & Number of deaths & Mortality (\%) \\
\hline A & 6 & $1 \times 10^{8}$ & 2 & 0 \\
B & 6 & $2 \times 10^{8}$ & 6 & 100 \\
C & 6 & $5 \times 10^{8}$ & 6 & 100 \\
\hline
\end{tabular}

437 A, B, and C represent groups given different challenge doses of $\mathrm{K} 88^{+}$ETEC. 
438 Table 6. Effects of antimicrobial peptides on ETEC $\mathrm{K} 88^{+}$infection in mice.

\begin{tabular}{ccccc}
\hline Group & $\begin{array}{l}\text { Number } \\
\text { mice }\end{array}$ & $\begin{array}{c}\text { of } \\
\text { Challenge } \\
\text { (CFU/mL) }\end{array}$ & $\begin{array}{c}\text { dose } \\
\text { Number of } \\
\text { deaths }\end{array}$ \\
\hline MRS & 6 & $2 \times 10^{8}$ & $6 / 6$ \\
pPG:612/L. casei 393 & 6 & $2 \times 10^{8}$ & $5 / 6$ \\
pPG:612-PR39/L. casei & 6 & $2 \times 10^{8}$ & $2 / 6$ \\
393 & & & \\
\hline
\end{tabular}


440

441

442

443

444

445

446

447

\section{Figure captions}

Figure 1. Analysis of the expressed product PR39 by western blotting. Lane 1, molecular mass marker; Lane 2, pellet of pPG:612/L. casei 393 induced by xylose; Lane 3, pellet of pPG:612-PR39/L. casei 393 induced by xylose, expressing a 36-kDa protein; Lane 4, supernatant of pPG:612/L. casei 393 induced by xylose; Lane 5, supernatant of pPG:612-PR39/L. casei 393 induced by xylose, expressing an 18-kDa protein.

Figure 2. Growth curves of recombinant bacteria without (a) and with (b) induction.

Figure 3. Antimicrobial activity of recombinant antibacterial peptide supernatants against Escherichia coli (a), Salmonella enterica ssp. enterica choleraesuis (b), and Staphylococcus aureus (c).

Figure 4. Jejunum $(\mathrm{A}-\mathrm{C})$ and duodenum $(\mathrm{E}-\mathrm{F})$ sections from laboratory mice $(100 \times)$. A. and E. Medium group; B. and D. Empty vector pPG:612/L. casei 393 group; C. and F. Recombinant strain pPG:612-PR39/L. casei 393 group. The villus height and intestinal crypt depth were measured in the duodenum and jejunum as representatives of intestinal health.

Figure 5. Amplification of $16 \mathrm{~S}$ rDNA V3. Lane M, DNA marker 5000 bp; Lane 1, mouse feces from the medium group at day 0; Lane 2, mouse feces from the pPG:612/ L. casei 393 group at day 0; Lane 3, mouse feces from the pPG:612-PR39/L. casei 393 group at day 0; Lane 4, mouse feces from the medium group at day 28; Lane 5, mouse feces from the pPG:612/L. casei 393 group at day 28; Lane 6, mouse feces from the pPG:612-PR39/L. casei 393 group at day 28; Lane 7, water control.

Figure 6. DGGE map of intestinal flora $16 \mathrm{~S}$ rDNA fragments from mouse feces. A0, mouse feces from the medium group at day 0; B0, mouse feces from the pPG:612/L. casei 393 group at day 0; C0, mouse feces from the pPG:612-PR39/L. casei 393 
465 group at day $0 ;$ A28, mouse feces from the medium group at day 28; B28, mouse 466 feces from the pPG:612/L. casei 393 group at day 28; C28, mouse feces from the 467 pPG:612-PR39/L. casei 393 group at day 28. 


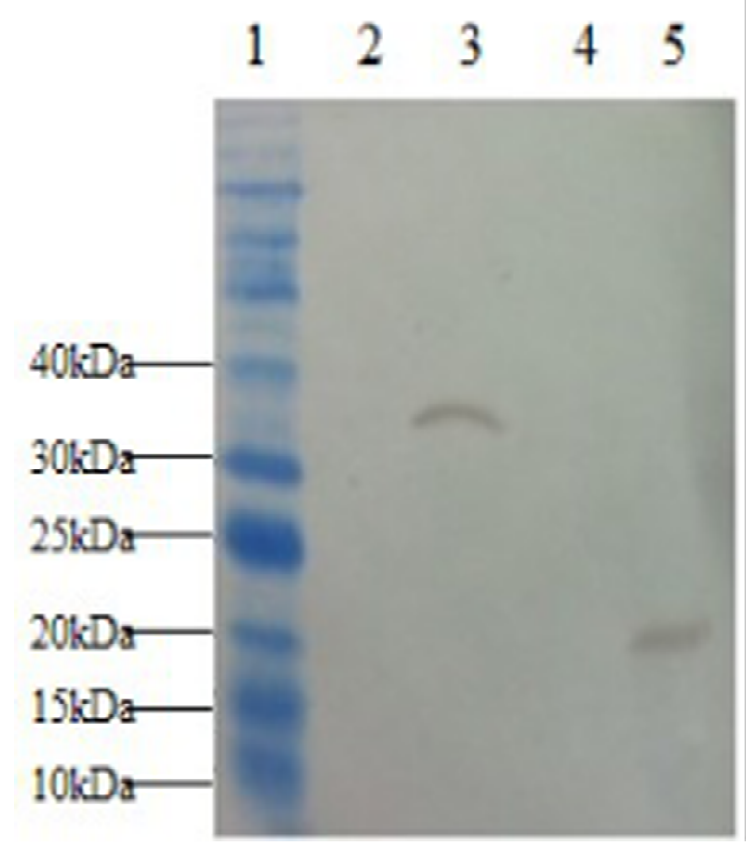

Figure 1. Analysis of the expressed product PR39 by Western blot. Lane 1, molecular mass marker; Lane2. The sediment of pPG:612/L.casei 393 inducing by xylose; Lane3. The sediment of pPG:612-PR39/L.casei 393 inducing by xylose, expressed a 36kDa proten; Lane4. The supernatant of pPG:612/L.casei 393 inducing by xylose; Lane5. The supernatant of pPG:612-PR39/L.casei 393 inducing by xylose, expressed a 18kDa proten. 


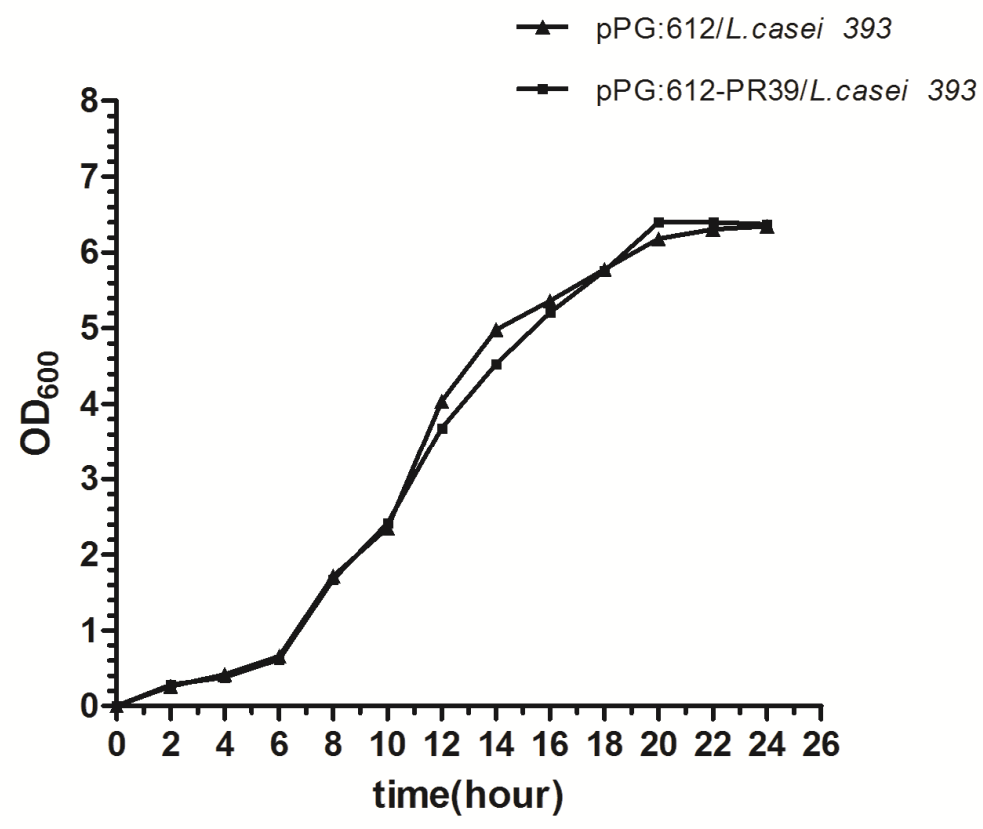

a

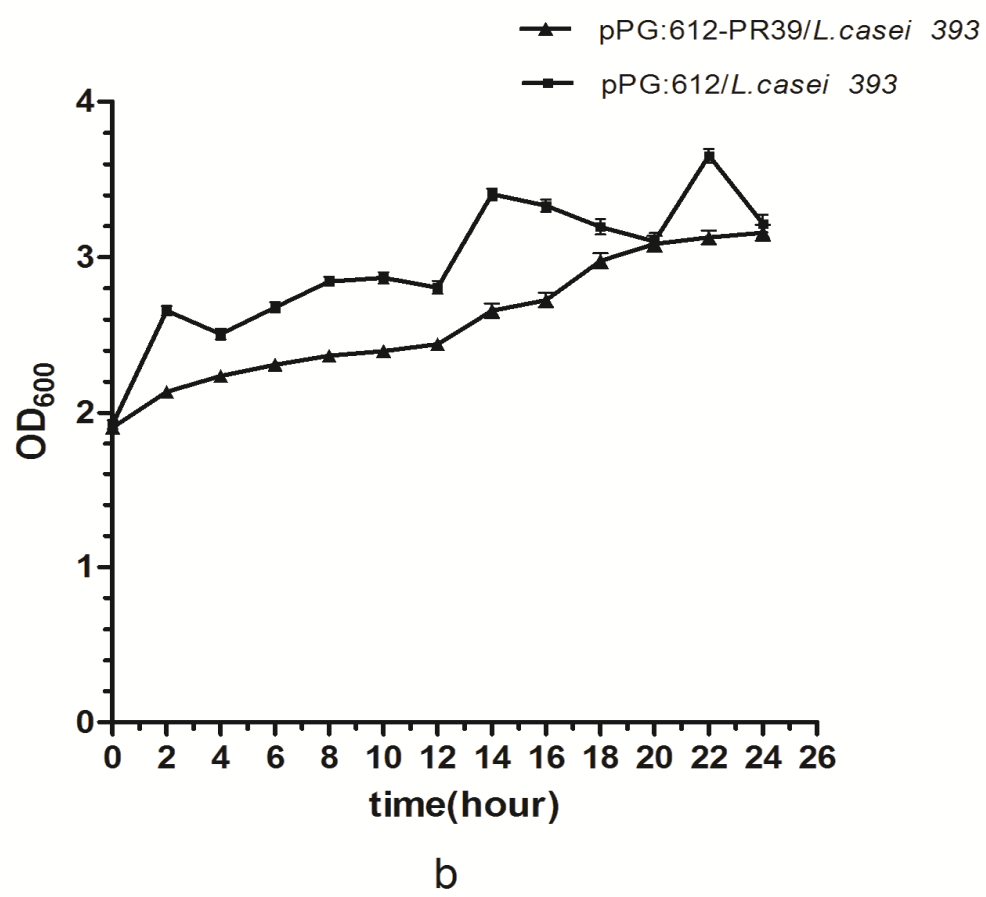

Figure 2. Growth curves of recombinant bacteria without (a) and with (b) induction. 


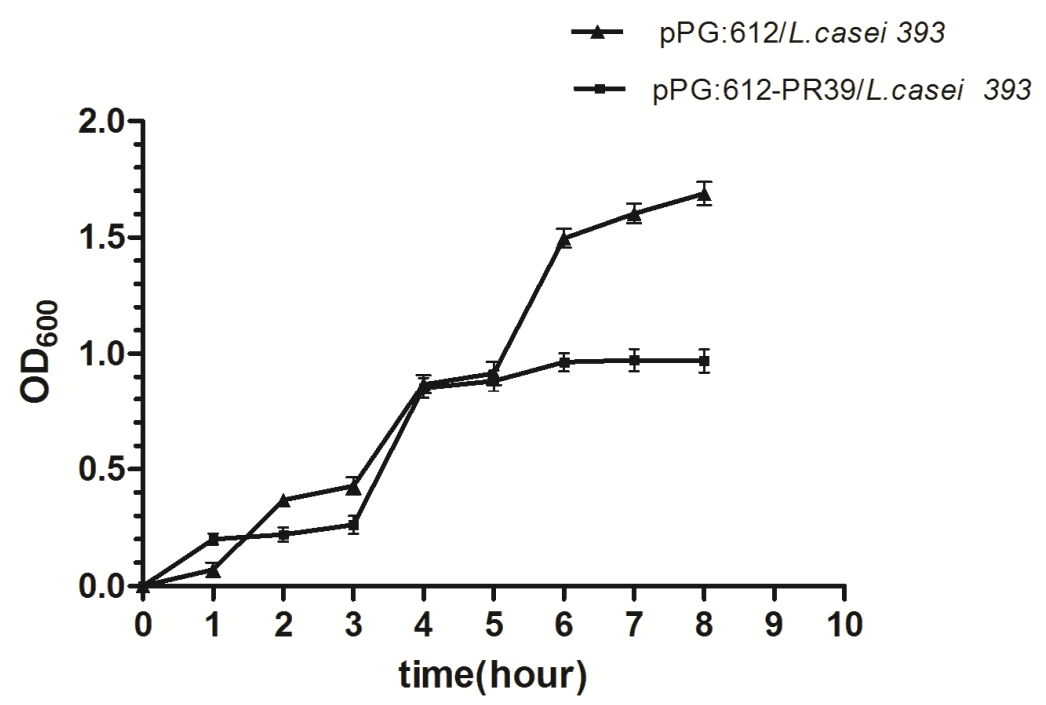

a

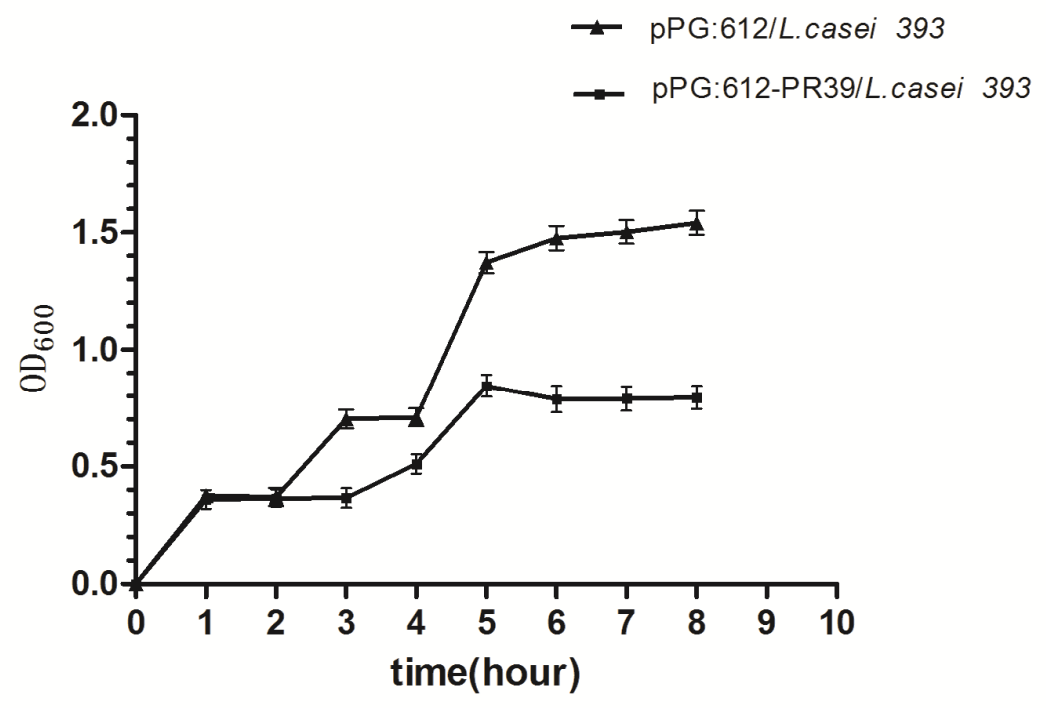

b 


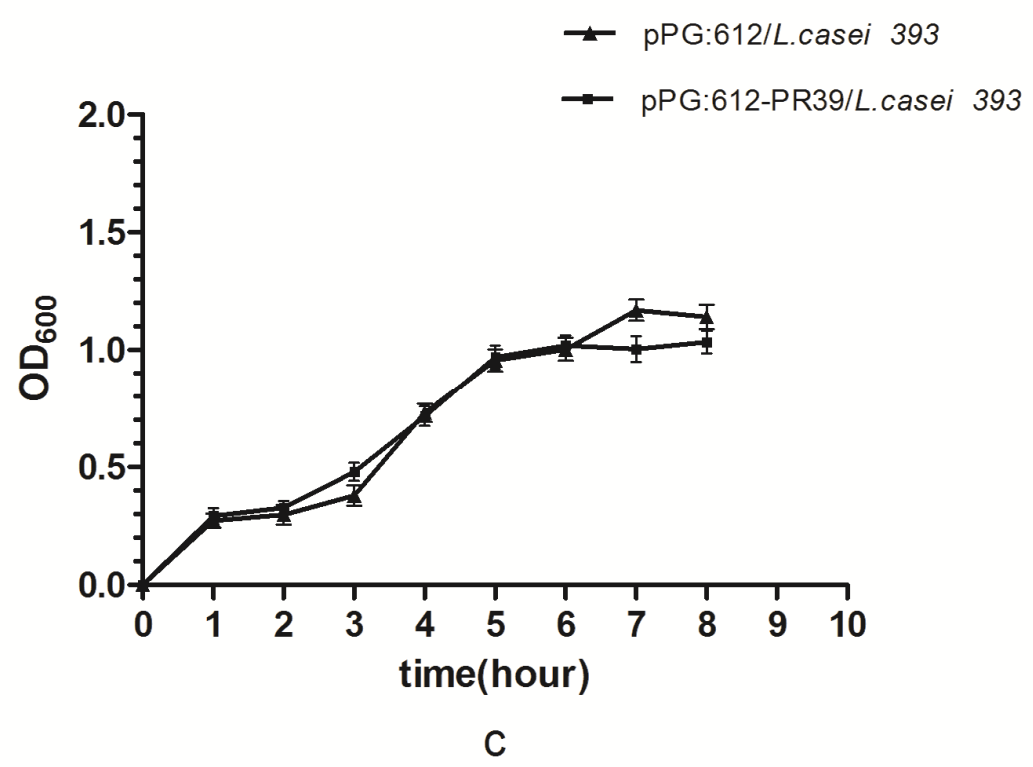

Figure 3. Antimicrobial activity of recombinant antibacterial peptide supernatants against Escherichia coli (a), Salmonella enterica ssp. enterica -choleraesuis (b), and Staphylococcus aureus (c). 

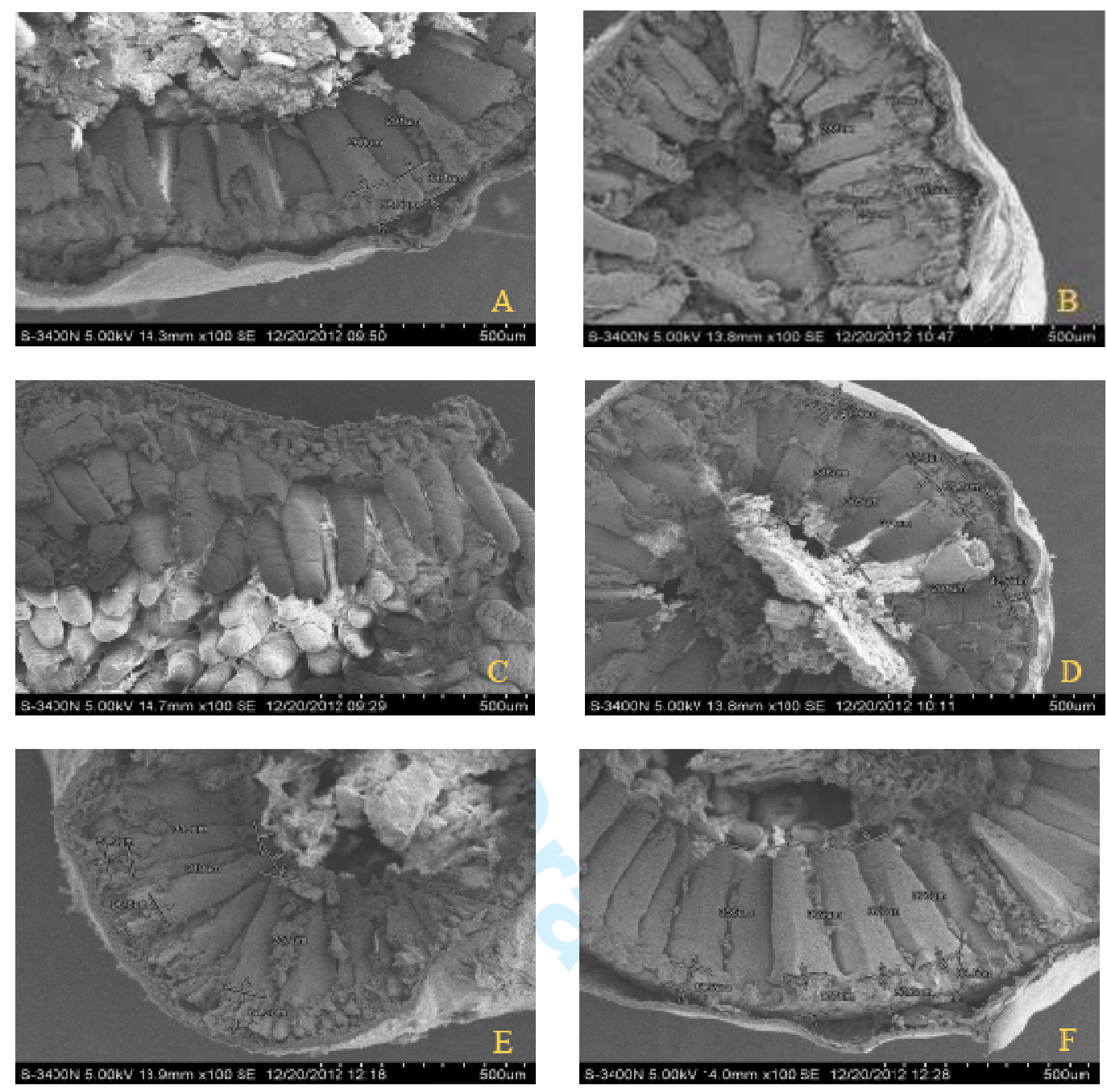

Figure 4. The jejunum $(A, B, C)$ and duodenum(E,D,F) sections of laboratory mice $(1 \times 100)$.

A.medium group; B. empty vector pPG:612/L.casei 393 group; C. recombinant strain pPG:612-PR39/L.casei 393 group; E. medium group; D. empty vector pPG:612/L.casei 393 group; F. recombinant strain pPG:612-PR39/L.casei 393 group. The villi height and Intestinal crypt depth of duodenum and jejunum were significantly higher in pPG:612-PR39/L.casei 393 group than those of control, which demonstrates an improvement of intestinal health. 


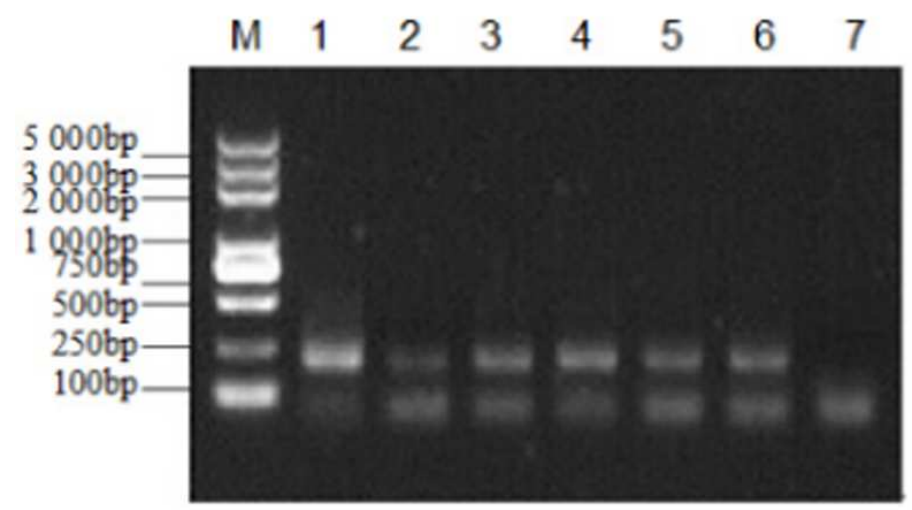

Figure 5. The amplified results of $16 \mathrm{~S}$ rDNA V3. Lane M. DNA Marker 5000bp; Lane 1. the mice feces of medium group at 0d; Lane 2. the mice feces of pPG:612/ L.casei 393 group at Od; Lane 3. the mice feces of pPG:612-PR39/L.casei 393 group at 0d; Lane 4. the mice feces of medium group at 28d; Lane 5. the mice feces of pPG:612/L.casei 393 group at 28d; Lane 6. the mice feces of pPG:612-PR39/L.casei 393 group at 28d; Lane 7. water control. 


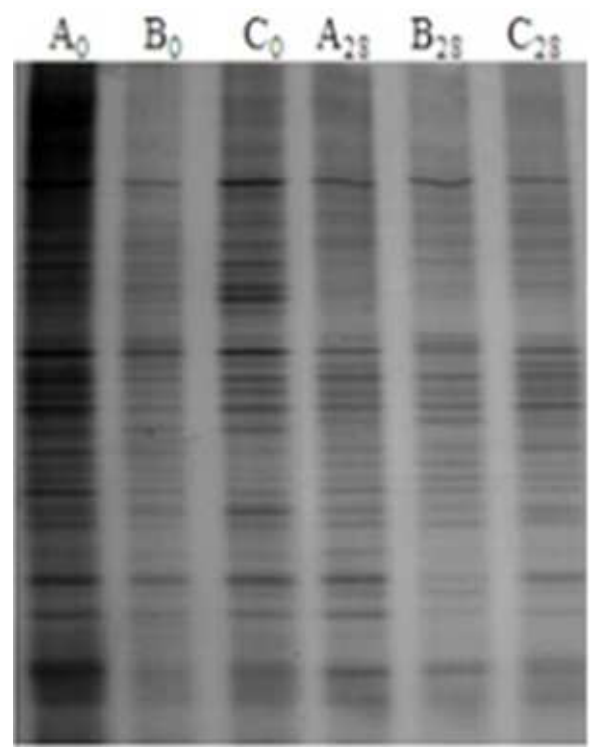

Figure 6. DGGE map of fungal $16 \mathrm{~S}$ rDNA fragments from the mice feces. A0. the mice feces of medium group at $\mathrm{Od} ; \mathrm{BO}$. the mice feces of pPG:612/L.casei 393 group at $0 \mathrm{~d} ; \mathrm{CO}$. the mice feces of pPG:612-PR39/L.casei 393 group at 0d; A28. the mice feces of medium group at 28d; B28. the mice feces of pPG:612/L.casei 393 group at 28d; C28. the mice feces of pPG:612-PR39/L.casei 393 group at $28 \mathrm{~d}$. 